\title{
Comportamiento del gel de sílice en el ensayo de puzolanicidad
}

M.a PILAR De luXaN, Dra. en Ciencias Químicas

\section{R E S U M E N}

Mediante el ensayo de puzolanicidad establecido en el PCCH 64 (que coincide con el RC-75), se ha realizado el estudio del comportamiento del gel de sílice como puzolana incorporado a un cemento.

Para ello se han preparado dos tipos de mezclas binarias, cemento portland-gel de sílice y cemento portland-puzolana natural, y mezclas ternarias cemento portland-puzolana-gel de sílice. Sobre cada una de ellas se ha determinado el índice de puzolanicidad, y se ha observado la influencia que ejerce la presencia del gel de sílice sobre las concentraciones de hidróxido cálcico y de iones alcalinos (sodio y potasio) existentes en el líquido que sobrenada la pasta de cemento portland.

\section{INTRODUCCION}

Siempre se ha considerado el gel de sílice como una puzolana de alta reactividad, ya que, por su carácter ácido, posee gran afinidad por el hidróxido cálcico, y por su estado físico, favorece la capacidad de reacción.

Este hecho ha motivado el presente estudio, en el que se consideran dos aspectos en el comportamiento de esta sustancia:

1) El gel de sílice como puzolana, incorporado en mezclas binarias con cemento portland.

2) El gel de sílice como puzolana patrón, incorporado en mezclas ternarias con cemento portland en presencia de puzolanas naturales.

Todas las observaciones se centran en el ensayo de puzolanicidad, establecido en el Pliego de Condiciones para la Recepción de Conglomerates Hidráulicos (1), para la valoración de cementos puzolánicos, y que se aplica a cada una de las mezclas preparadas.

Con respecto al primer punto, y por medio de este ensayo, es fundamental analizar el papel que juega el contenido de álcalis en la absorción de la cal.

En relación al segundo punto, interesa observar el efecto que produce la adición de gel de sílice a mezclas cemento portland/puzolana, que no satisfacen el ensayo de puzolanicidad debido a su bajo contenido de adición. El porcentaje de gel incorporado a la mezcla debe ser tal, que sumado a los efectos de la puzolana hace que la mezcla ternaria cumpla el índice de puzolanicidad. 
Este trabajo es complementario al ya publicado "Estudio y revisión crítica del ensayo de puzolanicidad" (2), en el que se estudian mezclas binarias cemento portland/puzolana natural, y al cual se aludirá en numerosas ocasiones, con objeto de no reiterar los mismos aspectos.

\section{PLAN DE TRABAJO}

\subsection{Materias primas}

Para la elaboración de las mezclas se utilizan como base, cuatro cementos portland (P-450, PAS-450, P-350 y PAS-350), y tres puzolanas naturales (de Almagro (Ciudad Real), Olot (Gerona) y Tenerife (Canarias), que se designarán respectivamente como puzolana A, B y C).

Como "puzolana patrón" se emplea el gel de sílice.

\subsection{Muestras preparadas}

a) Mezclas cemento portland-gel de sílice, en las proporciones $95 / 5 ; 90 / 10$ y 85/15.

b) Mezclas cemento portland-puzolanas naturales en las proporciones $90 / 10 ; 85 / 15$; $80 / 20$. Se omiten las mezclas con porcentajes de puzolana (70/30 y en adelante) pues para cualquiera que fuera el cemento y la puzolana, el ensayo de puzolanicidad de las mezclas resulta positivo tal como se exponía en el trabajo anterior (2).

c) Mezclas cemento portland-puzolanas naturales-gel de sílice. A los cementos del apartado b) que no cumplan los requisitos del ensayo de puzolanicidad ya sea a la edad de 7 como de 28 días, se les complementará con proporciones variables de gel de sílice, hasta que verifiquen el citado ensayo en las fechas preestablecidas.

\subsection{Ensayos}

Se aplica a todas las muestras preparadas el ensayo de puzolanicidad presente en el Pliego de Condiciones para la Recepción de Conglomerantes Hidráulicos (1), valorando no sólo la alcalinidad total (por neutralización con ácido clorhídrico y naranja de metilo como indicador) y el hidróxido cálcico (por permanganimetría y precipitación con oxalato) sino también, en la mayoría de los casos, el contenido de álcalis, sodio y potasio de la disolución, por fotometría de llama.

Se mide también de un modo aproximado el volumen del líquido residual que sobrenada en la pasta de cemento.

\section{RESULTADOS EXPERIMENTALES}

\subsection{Estudio de los materiales empleados}

\subsubsection{Cementos}

Su análisis químico (según PCCH 64, capítulo 2.71), incluidos los álcalis (determinados por fotometría de llama), así como su composición mineralógica potencial (calculada por 
las fórmulas de Bogue), los módulos de silicatos y fundentes y el índice de saturación en cal, se encuentran en la tabla I.

TAB L A I

Caracterización de los cementos

\begin{tabular}{|c|c|c|c|c|c|}
\hline & $\begin{array}{l}\text { Composición } \\
(\% \text { en peso) }\end{array}$ & P-450 & PAS-450 & P-350 & PAS-350 \\
\hline $\begin{array}{l}\text { Análisis } \\
\text { químico }\end{array}$ & $\begin{array}{l}\text { P.F. } \\
\text { R.I. } \\
\mathrm{SiO}_{2} \\
\mathrm{~A}_{2} \mathrm{O}_{3} \\
\mathrm{Fe}_{2} \mathrm{O}_{3} \\
\mathrm{CaO} \\
\mathrm{MgO} \\
\mathrm{SO}_{3} \\
\mathrm{Na}_{2} \mathrm{O} \\
\mathrm{K}_{2} \mathrm{O} \\
\mathrm{CaO} \text { libre }\end{array}$ & $\begin{array}{r}2,51 \\
0,33 \\
17,97 \\
5,94 \\
4,25 \\
62,76 \\
1,63 \\
3,38 \\
0,30 \\
0,83 \\
0,39\end{array}$ & $\begin{array}{r}3,24 \\
0,41 \\
20,50 \\
2,63 \\
5,70 \\
62,57 \\
0,72 \\
2,77 \\
0,24 \\
0,80 \\
0,29\end{array}$ & $\begin{array}{r}1,91 \\
0,20 \\
22,59 \\
4,95 \\
2,74 \\
63,39 \\
1,16 \\
2,64 \\
0,06 \\
0,36 \\
0,51\end{array}$ & $\begin{array}{r}2,45 \\
0,72 \\
20,29 \\
4,35 \\
6,63 \\
60,95 \\
1,51 \\
1,84 \\
0,06 \\
0,52 \\
0,98\end{array}$ \\
\hline $\begin{array}{l}\text { Composición } \\
\text { mineralógica } \\
\text { potencial } \\
\text { (F. Bogue) }\end{array}$ & $\begin{array}{l}\mathrm{C}_{3} \mathrm{~S} \\
\mathrm{C}_{2} \mathrm{~S} \\
\mathrm{C}_{3} \mathrm{~A} \\
\mathrm{C}_{4} \mathrm{AF} \\
\mathrm{C}_{2} \mathrm{~F}\end{array}$ & $\begin{array}{r}61,52 \\
5,25 \\
8,55 \\
12,92 \\
\end{array}$ & $\begin{array}{r}63,98 \\
10,60 \\
12,01 \\
3,00\end{array}$ & $\begin{array}{r}39,72 \\
34,80 \\
8,49 \\
8,33 \\
-\end{array}$ & $\begin{array}{r}46,10 \\
23,50 \\
0,33 \\
20,20 \\
\end{array}$ \\
\hline \multicolumn{2}{|c|}{$\begin{array}{l}\text { Módulo silicatos } \\
\text { Módulo fundentes } \\
\text { L.S.C. }\end{array}$} & $\begin{array}{r}1,76 \\
1,40 \\
100,00\end{array}$ & $\begin{array}{r}2,46 \\
0,46 \\
93,90\end{array}$ & $\begin{array}{r}2,94 \\
1,81 \\
86,40\end{array}$ & $\begin{array}{r}1,85 \\
0,65 \\
88,60\end{array}$ \\
\hline
\end{tabular}

\subsubsection{Puzolanas}

Su análisis químico se expresa en la tabla II, y se ha realizado partiendo de la disolución previa de la muestra, seca a $105^{\circ} \mathrm{C}$, mediante fusión alcalina.

T A B L A II

Análisis químico de las puzolanas naturales

\begin{tabular}{|c|c|c|c|}
\hline $\begin{array}{l}\text { Determinación } \\
(\% \text { en peso) }\end{array}$ & $\begin{array}{l}\text { Puzolana } \\
\text { Almagro } \\
\text { (A) }\end{array}$ & $\begin{array}{c}\text { Puzolana de } \\
\text { Olot } \\
\text { (B) }\end{array}$ & $\begin{array}{l}\text { Puzolana } \\
\text { Canaria } \\
\text { (C) }\end{array}$ \\
\hline $\begin{array}{l}\mathrm{P} . \mathrm{F} . \\
\mathrm{SiO}_{2} \\
\mathrm{Al}_{2} \mathrm{O}_{3} \\
\mathrm{Fe}_{2} \mathrm{O}_{3} \\
\mathrm{CaO} \\
\mathrm{MgO} \\
\mathrm{SO}_{3} \\
\mathrm{Na}_{2} \mathrm{O} \\
\mathrm{K}_{2} \mathrm{O}\end{array}$ & $\begin{array}{r}4,85 \\
42,01 \\
15,12 \\
12,22 \\
12,15 \\
11,55 \\
-\overline{1,30} \\
0,50\end{array}$ & $\begin{array}{r}0,31 \\
44,01 \\
18,45 \\
12,50 \\
10,32 \\
9,40 \\
-\overline{2,73} \\
1,72\end{array}$ & $\begin{array}{r}7,12 \\
52,60 \\
19,97 \\
3,03 \\
3,72 \\
2,26 \\
-1,69 \\
4,06\end{array}$ \\
\hline
\end{tabular}




\subsubsection{Gel de sílice}

El gel de sílice se sometió a la misma técnica analítica que las puzolanas: disolución de la muestra por fusión alcalina.

Los resultados obtenidos fueron los siguientes:

$\begin{array}{lr}\mathrm{SiO}_{2} & 90,00 \% \\ \text { P.F. } & 9,00 \% \\ \text { R.I. } & 0,45 \% \\ \text { Humedad }\left(105^{\circ} \mathrm{C}\right) & 16,40 \%\end{array}$

Este material se ha estudiado con anterioridad (3), para profundizar sobre su naturaleza y estructura, y se ha relacionado con su actividad frente a una disolución saturada de hidróxido cálcico, exenta de álcalis.

\subsection{Ensayo de puzolanicidad de las diferentes muestras}

Los resultados se expresan en las siguientes tablas y figuras (de acuerdo con el gráfico del estudio de la isoterma de solubilidad del $\mathrm{Ca}(\mathrm{OH})_{2}$ en presencia de álcalis tomado de N. Fratini y modificado):

Tabla III, figuras 1 y 2 (mezclas cemento portland-gel de sílice), tabla IV y figuras 3 y 4 (mezclas portland-puzolana de Almagro), tabla $\mathrm{V}$ y figuras 5 y 6 (mezclas portland-puzolana de Olot), tabla VI y figuras 7 y 8 (mezclas portland-puzolana de Canarias, tablas VII, VIII y IX y figuras $3,4,5,6,7$ y 8 (mezclas portland-puzolana-gel de sílice).

\subsection{Determinación de los álcalis}

Se determina por fotometría de llama el contenido de álcalis (sodio y potasio), en el líquido que sobrenada la pasta de cemento; de este modo se examina, en cierto grado, la velocidad de liberación de $\mathrm{Na}^{+}$y $\mathrm{K}^{+}$por la base portland, para las edades de 7 y 28 días, así como la capacidad de fijación de los mismos por el gel de sílice, para el mismo período. En la figura 9 se representa la concentración de cada uno de los álcalis en función del tiempo correspondiente a las mezclas cemento portland-gel de sílice. 
TAB L A III

Ensayo de puzolanicidad de las mezclas cemento portland-gel de sílice

\begin{tabular}{|c|c|c|c|c|c|c|c|}
\hline \multirow{2}{*}{$\begin{array}{l}\text { Edad } \\
\text { (días) }\end{array}$} & \multirow{2}{*}{$\begin{array}{c}\text { Cemento } \\
\text { base }\end{array}$} & \multirow{2}{*}{$\begin{array}{l}\text { Proporción } \\
\text { cemento/gel } \\
\text { de sílice }\end{array}$} & \multirow{2}{*}{$\begin{array}{l}\text { Alcalinidad } \\
\text { total } \\
\mathrm{mM} \mathrm{OH}^{-} / l\end{array}$} & \multirow{2}{*}{$\mathrm{CaO} \mathrm{mM} / l$} & \multicolumn{2}{|c|}{ Alcalis $\mathrm{mM} / l$} & \multirow{2}{*}{$\begin{array}{l}\text { Líquido } \\
\text { residual } \\
\text { (cc) }\end{array}$} \\
\hline & & & & & $\mathrm{Na}_{2} \mathrm{O}$ & $\mathrm{K}_{2} \mathrm{O}$ & \\
\hline 7 & $P-450$ & $\begin{array}{r}100 / 0 \\
95 / 5 \\
90 / 10 \\
85 / 15\end{array}$ & $\begin{array}{l}72,78 \\
54,26 \\
41,98 \\
32,76\end{array}$ & $\begin{array}{r}7,78 \\
12,90 \\
13,80 \\
11,50\end{array}$ & $\begin{array}{r}8,50 \\
3,95 \\
-2,26\end{array}$ & $\begin{array}{r}18,40 \\
4,95 \\
-1,01\end{array}$ & $\begin{array}{l}65,0 \\
50,0 \\
45,0 \\
45,0\end{array}$ \\
\hline 7 & PAS-450 & $\begin{array}{r}100 / 0 \\
95 / 5 \\
90 / 10 \\
85 / 15\end{array}$ & $\begin{array}{l}64,40 \\
49,40 \\
37,50 \\
31,50\end{array}$ & $\begin{array}{l}10,55 \\
14,70 \\
13,50 \\
14,35\end{array}$ & $\begin{array}{l}5,31 \\
3,30 \\
\overline{1,45}\end{array}$ & $\begin{array}{r}16,90 \\
5,21 \\
\overline{0,15}\end{array}$ & $\begin{array}{l}70,0 \\
72,5 \\
70,0 \\
63,0\end{array}$ \\
\hline 7 & PAS-350 & $\begin{array}{r}100 / 0 \\
95 / 5 \\
90 / 10 \\
85 / 15\end{array}$ & $\begin{array}{l}50,90 \\
42,50 \\
33,74 \\
30,40\end{array}$ & $\begin{array}{l}13,40 \\
17,90 \\
1,2,82 \\
14,05\end{array}$ & $\begin{array}{l}0,97 \\
1,21 \\
\overline{0,80}\end{array}$ & $\begin{array}{r}11,92 \\
3,72 \\
-0,69\end{array}$ & $\begin{array}{l}72,5 \\
72,0 \\
71,0 \\
70,0\end{array}$ \\
\hline 7 & P-350 & $\begin{array}{r}100 / 0 \\
95 / 5 \\
90 / 10 \\
85 / 15\end{array}$ & $\begin{array}{l}45.00 \\
42,00 \\
38,60 \\
30 ; 20\end{array}$ & $\begin{array}{l}15,80 \\
19,00 \\
18,60 \\
15,00\end{array}$ & $\begin{array}{l}1,07 \\
1,07 \\
0,43\end{array}$ & $\begin{array}{l}5,82 \\
1,99 \\
0, \overline{28}\end{array}$ & $\begin{array}{l}66,0 \\
68,0 \\
57,5 \\
66,0\end{array}$ \\
\hline 28 & P-450 & $\begin{array}{r}100 / 0 \\
95 / 5 \\
90 / 10 \\
85 / 15\end{array}$ & $\begin{array}{l}71,74 \\
59,00 \\
46,30 \\
44,00\end{array}$ & $\begin{array}{l}6,86 \\
6,76 \\
7,75 \\
9,81\end{array}$ & $\begin{array}{l}8,48 \\
8,42 \\
6,58 \\
6,05\end{array}$ & $\begin{array}{r}16,80 \\
12,15 \\
7,24 \\
3,98\end{array}$ & $\begin{array}{l}63,5 \\
49,5 \\
55,5 \\
54,5\end{array}$ \\
\hline 28 & PAS-450 & $\begin{array}{r}100 / 0 \\
95 / 5 \\
90 / 10 \\
85 / 15\end{array}$ & $\begin{array}{l}62,80 \\
51,40 \\
42,40 \\
33,80\end{array}$ & $\begin{array}{r}7,99 \\
8,04 \\
9,47 \\
11,60\end{array}$ & $\begin{array}{l}5,38 \\
5,16 \\
\overline{3,32}\end{array}$ & $\begin{array}{r}14,90 \\
8,17 \\
2,20\end{array}$ & $\begin{array}{l}73,0 \\
71,0 \\
71,5 \\
62,5\end{array}$ \\
\hline 28 & PAS-350 & $\begin{array}{r}100 / 0 \\
95 / 5 \\
90 / 10 \\
85 / 15\end{array}$ & $\begin{array}{l}52,00 \\
43,20 \\
34,80 \\
30,20\end{array}$ & $\begin{array}{l}10,43 \\
10,25 \\
11,63 \\
12,63\end{array}$ & $\begin{array}{l}1,61 \\
2,08 \\
\overline{1,51}\end{array}$ & $\begin{array}{r}13,78 \\
7,55 \\
\overline{1,06}\end{array}$ & $\begin{array}{l}62,5 \\
69,5 \\
67,5 \\
65,2\end{array}$ \\
\hline 28 & P-350 & $\begin{array}{r}100 / 0 \\
95 / 5 \\
90 / 10 \\
85 / 15\end{array}$ & $\begin{array}{l}44,20 \\
40,40 \\
35,00 \\
31,00\end{array}$ & $\begin{array}{l}13,10 \\
14,85 \\
15,30 \\
15,53\end{array}$ & $\begin{array}{r}2,23 \\
2,17 \\
\overline{1,07}\end{array}$ & $\begin{array}{r}6,47 \\
3,12 \\
\cdot \overline{0}, 35\end{array}$ & $\begin{array}{l}71,0 \\
68,2 \\
60,2 \\
71,7\end{array}$ \\
\hline
\end{tabular}


TAB L A IV

Ensayo de puzolanicidad de las mezclas cemento portland-puzolana de Almagro

\begin{tabular}{|c|c|c|c|c|c|c|c|}
\hline \multirow{2}{*}{$\begin{array}{l}\text { Edad } \\
\text { (días) }\end{array}$} & \multirow{2}{*}{$\begin{array}{c}\text { Cemento } \\
\text { base }\end{array}$} & \multirow{2}{*}{$\begin{array}{c}\text { Proporción } \\
\text { cementio/pu- } \\
\text { zolana }\end{array}$} & \multirow{2}{*}{$\begin{array}{c}\text { Alcalinidad } \\
\text { total } \\
\mathrm{mM} \mathrm{OH}^{-} / l\end{array}$} & \multirow{2}{*}{$\mathrm{CaO} \mathrm{mM} / l$} & \multicolumn{2}{|c|}{ Alcalis $\mathrm{mM} / \mathrm{l}$} & \multirow{2}{*}{$\begin{array}{l}\text { Líquido } \\
\text { residual } \\
\text { (cc) }\end{array}$} \\
\hline & & & & & $\mathrm{Na}_{2} \mathrm{O}$ & $\mathbf{K}_{2} \mathrm{O}$ & \\
\hline 7 & $P-450$ & $\begin{array}{l}90 / 10 \\
85 / 15 \\
80 / 20\end{array}$ & $\begin{array}{l}71,00 \\
69,00 \\
67,60\end{array}$ & $\begin{array}{l}7,69 \\
9,03 \\
8,28\end{array}$ & $\frac{8,23}{7,30}$ & $\frac{15,06}{13,99}$ & $\begin{array}{l}65,5 \\
65,5 \\
64,0\end{array}$ \\
\hline 7 & PAS-450 & $\begin{array}{l}90 / 10 \\
85 / 15 \\
80 / 20\end{array}$ & $\begin{array}{l}63,20 \\
66,80 \\
62,00\end{array}$ & $\begin{array}{r}9,95 \\
11,25 \\
11,65\end{array}$ & $\frac{5,45}{5,38}$ & $\frac{14,38}{1 \overline{2}, 07}$ & $\begin{array}{l}73,5 \\
74,5 \\
74,5\end{array}$ \\
\hline 7 & PAS-350 & $\begin{array}{l}90 / 10 \\
85 / 15 \\
80 / 20\end{array}$ & $\begin{array}{l}51,60 \\
52,40 \\
49,80\end{array}$ & $\begin{array}{l}12,34 \\
12,00 \\
11,31\end{array}$ & $\frac{1,51}{2,16}$ & $\frac{8,56}{8,42}$ & $\begin{array}{l}72,0 \\
73,5 \\
72,0\end{array}$ \\
\hline 7 & P-350 & $\begin{array}{l}90 / 10 \\
85 / 15 \\
80 / 20\end{array}$ & $\begin{array}{l}48,00 \\
48,60 \\
49,00\end{array}$ & $\begin{array}{l}16,32 \\
17,50 \\
15,68\end{array}$ & $\frac{1,69}{2,15}$ & $\frac{4,84}{4,94}$ & $\begin{array}{l}71,5 \\
71,0 \\
72,5\end{array}$ \\
\hline 28 & $P-450$ & $90 / 10$ & 72,80 & 5,88 & 10,70 & 17,40 & 57,0 \\
\hline 28 & P'AS-450 & $\begin{array}{l}90 / 10 \\
85 / 15\end{array}$ & $\begin{array}{l}66,60 \\
68,40\end{array}$ & $\begin{array}{l}7,20 \\
7,07\end{array}$ & $\frac{7,66}{-}$ & $\underline{15,20}$ & $\begin{array}{l}73,5 \\
71,5\end{array}$ \\
\hline 28 & PAS-350 & $\begin{array}{l}90 / 10 \\
85 / 15\end{array}$ & $\begin{array}{l}55,00 \\
57,00\end{array}$ & $\begin{array}{l}9,50 \\
9,85\end{array}$ & $\stackrel{3,54}{-}$ & $\stackrel{12,78}{-}$ & $\begin{array}{l}68,0 \\
70,0\end{array}$ \\
\hline 28 & P-350 & $\begin{array}{l}90 / 10 \\
85 / 15\end{array}$ & $\begin{array}{l}47,80 \\
48,40\end{array}$ & $\begin{array}{l}11,82 \\
11,20\end{array}$ & $\stackrel{3,22}{-}$ & $\underline{6,38}$ & $\begin{array}{l}63,3 \\
66,0\end{array}$ \\
\hline
\end{tabular}

T A в L A V

Ensayo de puzolanicidad de las mezclas cemento portland-puzolana de Olot

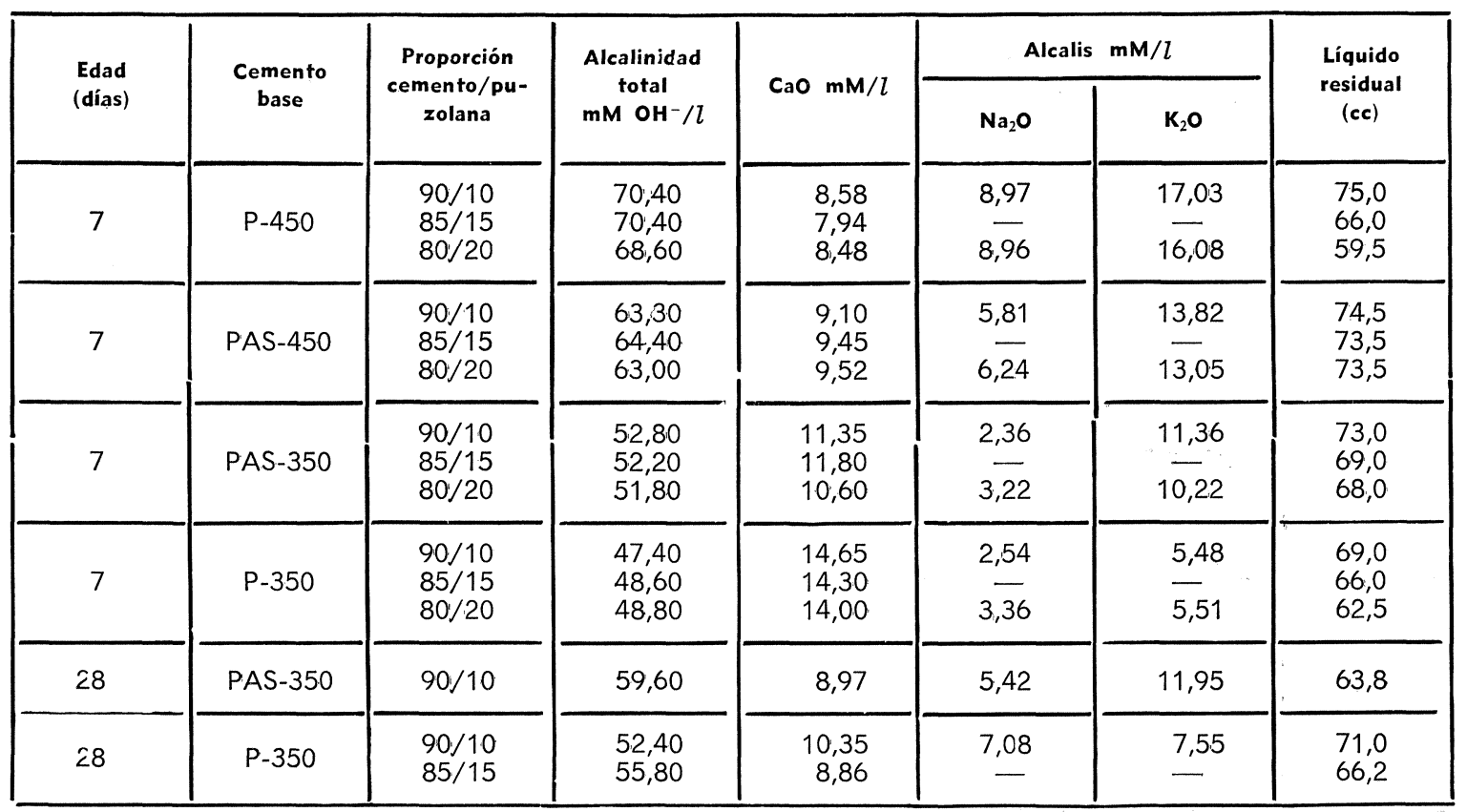


TA B L A VI

Ensayo de puzolanicidad de las mezclas de cemento portland-puzolana de Canarias

\begin{tabular}{|c|c|c|c|c|c|c|c|}
\hline \multirow{2}{*}{$\begin{array}{l}\text { Edad } \\
\text { (días) }\end{array}$} & \multirow{2}{*}{$\begin{array}{l}\text { Cemento } \\
\text { base }\end{array}$} & \multirow{2}{*}{$\begin{array}{l}\text { Proporción } \\
\text { cemento/pu- } \\
\text { zolana }\end{array}$} & \multirow{2}{*}{ 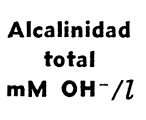 } & \multirow{2}{*}{$\mathrm{CaO} \mathrm{mM} / \mathrm{l}$} & \multicolumn{2}{|c|}{ Alcalis $\mathrm{mM} / l$} & \multirow{2}{*}{$\begin{array}{l}\text { Líquido } \\
\text { residual } \\
\text { (cc) }\end{array}$} \\
\hline & & & & & $\mathrm{Na}_{2} \mathrm{O}$ & $\mathrm{K}_{2} \mathrm{O}$ & \\
\hline 7 & P-450 & $\begin{array}{l}90 / 10 \\
85 / 15\end{array}$ & $\begin{array}{l}82,70 \\
96,60\end{array}$ & $\begin{array}{l}5,57 \\
4,83\end{array}$ & $\stackrel{17,20}{-}$ & $\stackrel{18,44}{-}$ & $\begin{array}{l}68,0 \\
66,0\end{array}$ \\
\hline 7 & PAS-450 & $90 / 10$ & $8 \varepsilon ; 00$ & 6,30 & 15,28 & 16,31 & 70,5 \\
\hline 7 & PAS-350 & $90 / 10$ & 68,40 & 7,01 & 10,35 & 13,08 & 67,5 \\
\hline 7 & P-350 & $\begin{array}{l}90 / 10 \\
85 / 15\end{array}$ & $\begin{array}{l}64,40 \\
71,40\end{array}$ & $\begin{array}{l}9,42 \\
6,43\end{array}$ & $\stackrel{11,42}{-}$ & 8,95 & $\begin{array}{l}64,0 \\
62,0\end{array}$ \\
\hline 28 & P-450 & $90 / 10$ & $96,60^{\circ}$ & 4,84 & 19,73 & 18,80 & 67,3 \\
\hline 28 & PAS-350 & $90 / 10$ & 76,00 & 6,31 & 12,23 & 15,40 & 70,0 \\
\hline
\end{tabular}

T A B L A VII

Ensayo de puzolanicidad de las mezclas cemento portland-puzolana de Almagro-gel de sílice

\begin{tabular}{|c|c|c|c|c|c|c|c|}
\hline \multirow{2}{*}{$\begin{array}{l}\text { Edad } \\
\text { (días) }\end{array}$} & \multirow{2}{*}{$\begin{array}{l}\text { Cemento } \\
\text { base }\end{array}$} & \multirow{2}{*}{$\begin{array}{c}\text { Proporción } \\
\text { cemento/pu- } \\
\text { zolana }+\mathrm{gel} \text { de } \\
\text { sílice } / 1.000 \mathrm{~g}\end{array}$} & \multirow{2}{*}{$\begin{array}{l}\text { Alcalinidad } \\
\text { total } \\
\mathrm{mM} \mathrm{OH}^{-} / l\end{array}$} & \multirow{2}{*}{$\mathrm{CaO} \mathrm{mM} / l$} & \multicolumn{2}{|c|}{ Alcalis $\mathbf{m} \mathbf{M} / l$} & \multirow{2}{*}{$\begin{array}{l}\text { Líquido } \\
\text { residual } \\
\text { (cc) }\end{array}$} \\
\hline & & & & & $\mathrm{Na}_{2} \mathrm{O}$ & $\mathrm{K}_{2} \mathrm{O}$ & \\
\hline 7 & $P-450$ & $\begin{array}{l}90 / 10+75 \mathrm{~g} \\
85 / 15+60 \mathrm{~g} \\
85 / 15+50 \mathrm{~g} \\
80 / 20+50 \mathrm{~g} \\
80 / 20+25 \mathrm{~g}\end{array}$ & $\begin{array}{l}45,00 \\
43,60 \\
49,60 \\
45,50 \\
55,60\end{array}$ & $\begin{array}{r}11,02 \\
8,34 \\
8,50 \\
6,12 \\
6,73\end{array}$ & $\frac{6,34}{=}$ & $\begin{array}{l}\frac{5,68}{E} \\
\overline{-} \\
8,32\end{array}$ & $\begin{array}{l}59,0 \\
61,0 \\
61,2 \\
56,5 \\
59,0\end{array}$ \\
\hline 7 & PAS-450 & $\begin{array}{l}90 / 10+75 \mathrm{~g} \\
85 / 15+50 \mathrm{~g} \\
80 / 20+25 \mathrm{~g}\end{array}$ & $\begin{array}{l}42,40 \\
46,00 \\
51,80\end{array}$ & $\begin{array}{r}12,92 \\
11,15 \\
9,74\end{array}$ & $\frac{2,58}{5,57}$ & $\frac{3,41}{8.37}$ & $\begin{array}{l}68,8 \\
76,0 \\
75,0\end{array}$ \\
\hline 7 & PAS-350 & $\begin{array}{l}90 / 10+75 \mathrm{~g} \\
85 / 15+50 \mathrm{~g} \\
80 / 20+25 \mathrm{~g}\end{array}$ & $\begin{array}{l}35,80 \\
38,80 \\
42,00\end{array}$ & $\begin{array}{l}13,10 \\
12,80 \\
11,79\end{array}$ & $\frac{1,61}{2,18}$ & $\frac{2,84}{7,61}$ & $\begin{array}{l}71,5 \\
69,2 \\
68,0\end{array}$ \\
\hline 7 & P-350 & $\begin{array}{l}90 / 10+95 \mathrm{~g} \\
90 / 10+75 \mathrm{~g} \\
85 / 15+50 \mathrm{~g} \\
80 / 20+50 \mathrm{~g} \\
80 / 20+25 \mathrm{~g}\end{array}$ & $\begin{array}{l}34,00 \\
40,00 \\
41,60 \\
38,60 \\
45,00\end{array}$ & $\begin{array}{l}14,22 \\
17,50 \\
16,10 \\
13,05 \\
15,55\end{array}$ & $\frac{\overline{1,51}}{\overline{2} \overline{15}}$ & $\begin{array}{l}\overline{0,99} \\
\bar{z} \\
2,84\end{array}$ & $\begin{array}{l}58,5 \\
68,0 \\
70,5 \\
62,6 \\
68,5\end{array}$ \\
\hline 28 & P-450 & $90 / 10+25 \mathrm{~g}$ & 67,20 & 4,76 & 12,30 & 14,27 & 60,0 \\
\hline 28 & PAS-450 & $\begin{array}{l}90 / 10+50 \mathrm{~g} \\
85 / 15+25 \mathrm{~g}\end{array}$ & $\begin{array}{l}52,00 \\
61,40\end{array}$ & $\begin{array}{l}6,65 \\
7,52\end{array}$ & $\begin{array}{l}8,12 \\
9,45\end{array}$ & $\begin{array}{l}10,43 \\
13,04\end{array}$ & $\begin{array}{l}65,8 \\
68,2\end{array}$ \\
\hline 28 & PAS-350 & $\begin{array}{l}90 / 10+50 \mathrm{~g} \\
85 / 15+25 \mathrm{~g}\end{array}$ & $\begin{array}{l}45,40 \\
51,40\end{array}$ & $\begin{array}{l}8,65 \\
9,52\end{array}$ & $\begin{array}{l}4,72 \\
5,21\end{array}$ & $\begin{array}{l}9,68 \\
9,81\end{array}$ & $\begin{array}{l}63,0 \\
63,3\end{array}$ \\
\hline 28 & $P-350$ & $\begin{array}{l}90 / 10+50 \mathrm{~g} \\
85 / 15+25 \mathrm{~g}\end{array}$ & $\begin{array}{l}44,40 \\
47,60\end{array}$ & $\begin{array}{l}12,10 \\
11,10\end{array}$ & $\begin{array}{l}4,08 \\
5,38\end{array}$ & $\begin{array}{l}5,38 \\
5,18\end{array}$ & $\begin{array}{l}65,5 \\
69,5\end{array}$ \\
\hline
\end{tabular}


TABLA VIII

Ensayo de puzolanicidad de las mezclas cemento portland-puzolana de Olot-gel de sílice

\begin{tabular}{|c|c|c|c|c|c|c|c|}
\hline \multirow{2}{*}{$\begin{array}{l}\text { Edad } \\
\text { (días) }\end{array}$} & \multirow{2}{*}{$\begin{array}{l}\text { Cemento } \\
\text { base }\end{array}$} & \multirow{2}{*}{$\begin{array}{c}\text { Proporción } \\
\text { cemento } / \mathrm{pu}- \\
\text { zolana }+\mathrm{gel} \text { de } \\
\text { silice } / 1.000 \mathrm{~g}\end{array}$} & \multirow{2}{*}{$\begin{array}{l}\text { Alcalinidad } \\
\text { total } \\
\mathrm{mM} \mathrm{OH}^{-} / l\end{array}$} & \multirow{2}{*}{$\mathrm{CaO} \mathrm{mM} / \mathrm{l}$} & \multicolumn{2}{|c|}{ Alcalis $\mathrm{mM} / l$} & \multirow{2}{*}{$\begin{array}{l}\text { Líquido } \\
\text { residual } \\
\text { (cc) }\end{array}$} \\
\hline & & & & & $\mathrm{Na}_{2} \mathrm{O}$ & $\mathrm{K}_{2} \mathrm{O}$ & \\
\hline 7 & P-450 & $\begin{array}{l}90 / 10+75 \mathrm{~g} \\
85 / 15+50 \mathrm{~g} \\
80 / 20+25 \mathrm{~g}\end{array}$ & $\begin{array}{l}45,40 \\
50,20 \\
57,00\end{array}$ & $\begin{array}{r}10,50 \\
8,46 \\
7,49\end{array}$ & $\frac{5,27}{7,83}$ & $\frac{4,<0}{9,61}$ & $\begin{array}{l}61,3 \\
61,2 \\
66,5\end{array}$ \\
\hline 7 & PAS-450 & $\begin{array}{l}90 / 10+75 \mathrm{~g} \\
85 / 15+50 \mathrm{~g} \\
80 / 20+25 \mathrm{~g}\end{array}$ & $\begin{array}{l}42,60 \\
46,60 \\
51,00\end{array}$ & $\begin{array}{r}12,55 \\
11,75 \\
9,84\end{array}$ & $\frac{2,63}{7,18}$ & $\frac{3,62}{8, \overline{74}}$ & $\begin{array}{l}74,0 \\
72,0 \\
69,0\end{array}$ \\
\hline 7 & PAS-350 & $\begin{array}{l}90 / 10+75 \mathrm{~g} \\
85 / 15+50 \mathrm{~g} \\
80 / 20+25 \mathrm{~g}\end{array}$ & $\begin{array}{l}36,20 \\
38,20 \\
43,80\end{array}$ & $\begin{array}{l}12,60 \\
11,75 \\
10,71\end{array}$ & $\frac{2,60}{3,73}$ & $\frac{3,21}{6,52}$ & $\begin{array}{l}70,6 \\
69,4 \\
68,5\end{array}$ \\
\hline 7 & P-350 & $\begin{array}{l}90 / 10+100 \mathrm{~g} \\
90 / 10+75 \mathrm{~g} \\
85 / 15+75 \mathrm{~g} \\
85 / 15+50 \mathrm{~g} \\
80 / 20+50 \mathrm{~g} \\
80 / 20+25 \mathrm{~g}\end{array}$ & $\begin{array}{l}35,60 \\
40,00 \\
38,00 \\
41,40 \\
40,00 \\
44,60\end{array}$ & $\begin{array}{l}14,95 \\
16,91 \\
15,59 \\
15,80 \\
14,60 \\
15,48\end{array}$ & $\begin{array}{l}1,68 \\
1,32 \\
- \\
2,89 \\
2,56\end{array}$ & $\begin{array}{l}1,10 \\
1,02 \\
-\overline{1} \\
1,91 \\
2,11\end{array}$ & $\begin{array}{l}60,3 \\
65,5 \\
61,4 \\
68,5 \\
69,2 \\
72,0\end{array}$ \\
\hline 28 & PAS-350 & $90 / 10+25 \mathrm{~g}$ & 50,80 & 6,25 & 7,42 & 11,70 & 60,5 \\
\hline 28 & P-350 & $\begin{array}{l}90 / 10+50 \mathrm{~g} \\
85 / 15+25 \mathrm{~g}\end{array}$ & $\begin{array}{l}43,20 \\
49,80\end{array}$ & $\begin{array}{r}10,85 \\
7,90\end{array}$ & $\begin{array}{l}5,97 \\
7,87\end{array}$ & $\begin{array}{l}4,77 \\
6,40\end{array}$ & $\begin{array}{l}62,7 \\
64,5\end{array}$ \\
\hline
\end{tabular}

TAB L A IX

Ensayo de puzolanicidad de las mezclas cemento portland-puzolana de Canarias-gel de sílice

\begin{tabular}{|c|c|c|c|c|c|c|c|}
\hline \multirow{2}{*}{$\begin{array}{l}\text { Edad } \\
\text { (días) }\end{array}$} & \multirow{2}{*}{$\begin{array}{l}\text { Cemento } \\
\text { base }\end{array}$} & \multirow{2}{*}{$\begin{array}{c}\text { Proporción } \\
\text { cemento/pu- } \\
\text { zolana }+\mathrm{gel} \text { de } \\
\text { sílice } / 1.000 \mathrm{~g}\end{array}$} & \multirow{2}{*}{$\begin{array}{c}\begin{array}{c}\text { Alcalinidad } \\
\text { total }\end{array} \\
\mathrm{mM} \mathrm{OH}^{-} / l\end{array}$} & \multirow{2}{*}{$\mathrm{CaO} \mathrm{mM} / \mathrm{l}$} & \multicolumn{2}{|c|}{ Alcalis $\mathrm{mM} / l$} & \multirow{2}{*}{$\begin{array}{l}\text { Líquido } \\
\text { residual } \\
\text { (cc) }\end{array}$} \\
\hline & & & & & $\mathrm{Na}_{2} \mathrm{O}$ & $\mathrm{K}_{2} \mathrm{O}$ & \\
\hline 7 & $P-450$ & $\begin{array}{l}90 / 10+50 \mathrm{~g} \\
85 / 15+25 \mathrm{~g}\end{array}$ & $\begin{array}{l}63,20 \\
84,00\end{array}$ & $\begin{array}{l}4,70 \\
3,20\end{array}$ & $\begin{array}{l}15,30 \\
22,24\end{array}$ & $\begin{array}{r}9,46 \\
14,68\end{array}$ & $\begin{array}{l}63,7 \\
62,4\end{array}$ \\
\hline 7 & PAS-450 & $90 / 10+25 \mathrm{~g}$ & 68,40 & 6,84 & 13,63 & 10,70 & $80 ; 0$ \\
\hline 7 & PAS-350 & $90 / 10+25 \mathrm{~g}$ & 59,20 & 8,76 & 11,05 & $9 ; 54$ & 70,5 \\
\hline 7 & $P-350$ & $\begin{array}{l}90 / 10+50 \mathrm{~g} \\
85 / 15+25 \mathrm{~g}\end{array}$ & $\begin{array}{l}49,80 \\
60,80\end{array}$ & $\begin{array}{r}10,87 \\
6,16\end{array}$ & $\begin{array}{r}9,82 \\
15,33\end{array}$ & $\begin{array}{l}3,82 \\
7,34\end{array}$ & $\begin{array}{l}70,5 \\
70,5\end{array}$ \\
\hline 28 & $P-450$ & $90 / 10+25 \mathrm{~g}$ & 94,50 & 4,00 & 24,18 & 18,80 & 48,5 \\
\hline 28 & PAS-350 & $90 / 10+25 \mathrm{~g}$ & 70,00 & 6,25 & 14,44 & 12,80 & 62,0 \\
\hline
\end{tabular}




\section{INTERPRETACION DE RESULTADOS}

\subsection{Ensayo de puzolanicidad}

La interpretación de los resultados obtenidos en la aplicación del ensayo de puzolanicidad a las muestras preparadas, se centra en el gel de sílice, y se observa su comportamiento en mezclas binarias con cementos portland y ternarias con cementos con puzolana. [Los cementos portland puros y las mezclas portland-puzolana han sido ya estudiadas (2)].

La adición de gel de sílice produce diversos efectos en la hidratación de los cementos.

En primer lugar se observa como su presencia reduce notablemente el volumen de los líquidos residuales, destacando el P-450, y tanto más cuanto más elevado es el contenido de gel. Esto se debe: en parte, a la elevada finura del cemento, que produce una mayor velocidad de hidratación del gel de sílice creando hidratos de elevado contenido de agua $\mathrm{y}$, finalmente también, a una elevada consistencia normal de la pasta por la presencia de aluminatos cálcicos. Los cementos PAS consumen menos agua que los cementos portland normales (4).

Otro hecho que se aprecia al incorporar gel de sílice al cemento, es la reducción de la alcalinidad total en todos los casos, pero con aumento del contenido de $\mathrm{Ca}(\mathrm{OH})_{2}$ en la disolución. Este efecto se produce tanto a 7 como a 28 días. Puede justificarse al considerar la fijación preferencial de los óxidos alcalinos por el gel, aun cuando también se produzca más tarde la fijación de cal (efecto puzolánico) dada la facilidad con que se sitúan los puntos por debajo de la curva de saturación.

En el análisis de las mezclas ternarias, cementos portland con bajo porcentaje de puzolana adicionados de gel de sílice cabe destacar los siguientes puntos:

- La cantidad de gel que se necesita añadir a un cemento portland para cumplir el ensayo de puzolanicidad disminuye al aumentar la saturación en cal del cemento. Así, el cemento P-450 cumple el ensayo a 7 días con el $5 \%$ y a 28 días con el $2,5 \%$ de gel, en tanto que el cemento P-350, requiere $12 \%$ de gel a 7 días y $5 \%$ a 28 días. Es decir, el tratar de establecer el gel de sílice como puzolana patrón sería más factible en cementos de baja saturación (figuras 1 y 2).

- El gel de sílice complementario para cumplir el ensayo de puzolanicidad en los cementos portland que contienen puzolana en porcentaje bajo, sigue la norma antes señalada: a mayor saturación en cal del cemento portland, menor es la proporción de gel. Esto se acusa además porque la propia puzolana sola aumenta su actividad con la saturación en cal del cemento, así, mientras la puzolana B cumple a 28 días con el $8 \%$ en los dos cementos P-450 y PAS-450, con los cementos PAS-350 y P-350 requiere el 13 y $16 \%$, respectivamente, para cumplir el ensayo a la misma edad. Esto puede observarse gráficamente en las figuras $3,4,5$ y 6 .

- A su vez la puzolana C cumple en general, fácilmente el ensayo de puzolanicidad al complementarse su actividad con el gel de sílice (figs. 7 y 8); esto ocurre con cualquiera de los cementos portland. En algunos casos, como son los cementos P-350 y PAS-350 ambos con $10 \%$ de puzolana y a la edad de 7 días, al ser adicionados con el gel de sílice experimentan en el ensayo una disminución fuerte de alcalinidad total, acompañada de una elevación en el contenido de cal de la solución, en cierto modo semejante a lo ocurrido en las mezclas cemento-gel de sílice.

De todos modos, para altas adiciones de puzolana (superiores al $15 \%$ ) el porcentaje de gel necesario para cumplir el ensayo de puzolanicidad es siempre inferior al requerido por los portland sólos. Esto es un indicio de las posibilidades de emplear el gel de sílice 
como puzolana patrón. Sin embargo esta idea no es factible ya que en el caso de las mezclas ternarias camento portland-puzolana-gel de sílice, existe interferencia entre las acciones de las puzolanas y del gel de sílice, especialmente a primeras edades.

\subsection{Los álcalis}

La evolución del contenido de álcalis en los líquidos residuales, se observa de modo independiente para el sodio y el potasio.

El porcentaje de álcalis aumenta siempre, en una misma muestra, al pasar de 7 a 28 días, destacando el aumento de contenido en sodio respecto del potasio.

En los cementos con gel de sílice como adición única, el efecto es siempre el mismo: fuerte disminución del contenido de sodio y potasio al elevar el contenido de gel (fig. 9). La reducción es más importante para el potasio, cuya concentración es prácticamente nula en las mezclas con porcentajes de gel más elevados.

La adición de gel a los cementos con puzolana reduce siempre de un modo notable el contenido de álcalis tanto de sodio como de potasio (tablas VII y VIII).

\subsection{El gel de sílice como puzolana respecto al ensayo de puzolanicidad}

El comportamiento del gel de sílice observado a través del ensayo de puzolanicidad, refleja:

- El gel de sílice actúa como una puzolana frente al hidróxido cálcico, a partir ya de las primeras edades (3), pero si existen álcalis (sodio y potasio) simultáneamente en la disolución, el gel de sílice los fija selectivamente y principalmente el potasio (figura 9), por lo que la cal permanece en la disolución (figs. 1 y 2), así pues no se puede hablar de una acción puzolánica del gel de sílice, en su sentido estricto de reacción con cal; en las mezclas binarias de cemento portland-gel de sílice.

El hecho de que el gel de sílice no fije el $\mathrm{Ca}(\mathrm{OH})_{2}$ e incluso eleve su concentración en el líquido conforme aumenta el porcentaje de gel incorporado al cemento, puede deberse a varias causas:

- La concentración de hidróxido cálcico en la disolución aumenta por efecto ion común, al disminuir las concentraciones de $\mathrm{Na}^{+} \mathrm{y} \mathrm{K}^{+}$, que son fijadas selectivamente por el gel de sílice.

- La afinidad del gel de sílice por los álcalis puede provocar una hidratación más profunda del cemento con la consiguiente liberación de hidróxido cálcico, que pasa, en parte, al líquido que sobrenada la pasta de cemento, incrementando su concentración en él.

El gel de sílice provoca una disminución en la alcalinidad total, por la fijacción de los álcalis, a diferencia de las puzolanas naturales, donde se observa un incremento de esta alcalinidad total de la disolución ya que se suman dos efectos, por una parte liberan sus propios álcalis que se incorporan al líquido, y por otra parte al fijar el hidróxido cálcico, se eleva la concentración de álcalis en la solución; destaca este hecho en la puzolana C, cuyo contenido en álcalis es el más elevado (tabla II) (2).

La disminución de la alcalinidad total, existente en la mayoría de los casos, motivada por la presencia del gel de sílice, se observa tanto en las mezclas binarias cemento portlandgel de sílice (figs. 1 y 2), como en las ternarias cemento portland-puzolana-gel de sílice (figs. 3, 4, 5, 6, 7 y 8), especialmente en aquellas cuyo cemento base es de alta saturación en cal, ya que se corresponden con las de mayor contenido en álcalis (tabla I). 


\section{CONCLUSIONES}

1) La adición de gel de sílice a los cementos portland reduce considerablemente el contenido de los óxidos alcalinos en los líquidos residuales, así como el volumen de los mismos.

2) El gel de sílice fija selectivamente el potasio, y, en general, los álcalis, frente al hidróxido cálcico.

3) El gel de sílice actúa como puzolana respecto al ensayo de puzolanicidad, ya que cumple el índice señalado, puesto que la disolución queda no saturada en cal por efecto de los álcalis, sin embargo, en la mayoría de los casos, la concentración de hidróxido cálcico del líquido aumenta, ya que no es fijado por el gel de sílice, mientras existan simultáneamente potasio y sodio en solución.

\section{B I B L I O G R A F I A}

(1) Pliego de Condiciones para la Recepción de Conglomerantes Hiaráulicos. (PCCH 64). B.O.E. 6/5/1974; (RC-75). B.O.E. 28-29/8/1975.

(2) De LuXan, M. P., Soria, F.: "Study and Critical Review of the Pozzolanity Test". Cem. Concr. Res., 5, 5, 461-480, (1975).

(3) DE LUXAN, M. P., VazQUez, T.: "Il gelo di silice come pozzolana di riferimento: sua notevole attivita e soui limiti". Il Cemento, 71, 3, 113-130, (1974). "Materiales de Construcción n. 160, págs. 79-95 (1975).

(4) SORIA, F.: “Contribución al estudio de los cementos portland resistentes a sulfatos" Ed. I.E.T.c.c. Madrid, (1966). 
CURVA ISOTERMA DE SOLUBILIDAD A $40^{\circ} \mathrm{C}$ DE $\mathrm{Ca}(\mathrm{OH})_{2}$, EN PRESENCIA DE ALCALIS, DE NICOLA FRATINI, TOMADA PARA EL ENSAYO DE PUZOLANICIDAD

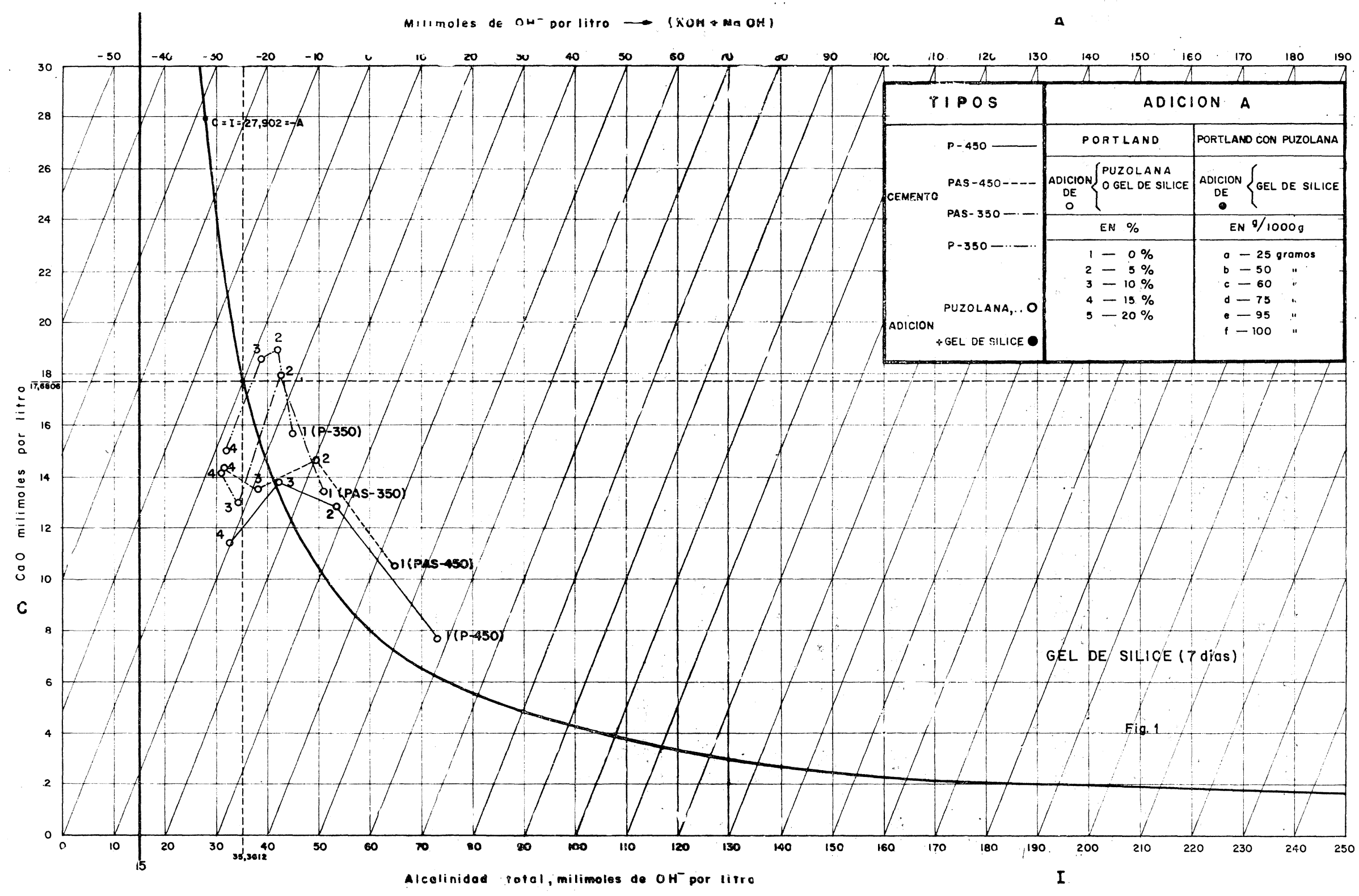


CURVA ISOTERMA DE SOlUbILIDAD A $40^{\circ} \mathrm{C}$ DE Ca(OH) $)_{2}$, EN PRESENCIA DE ALCALIS, DE NICOLA FRATINI, tOMADA PARA EL ENSAYO DE PUZOLANICIDAD

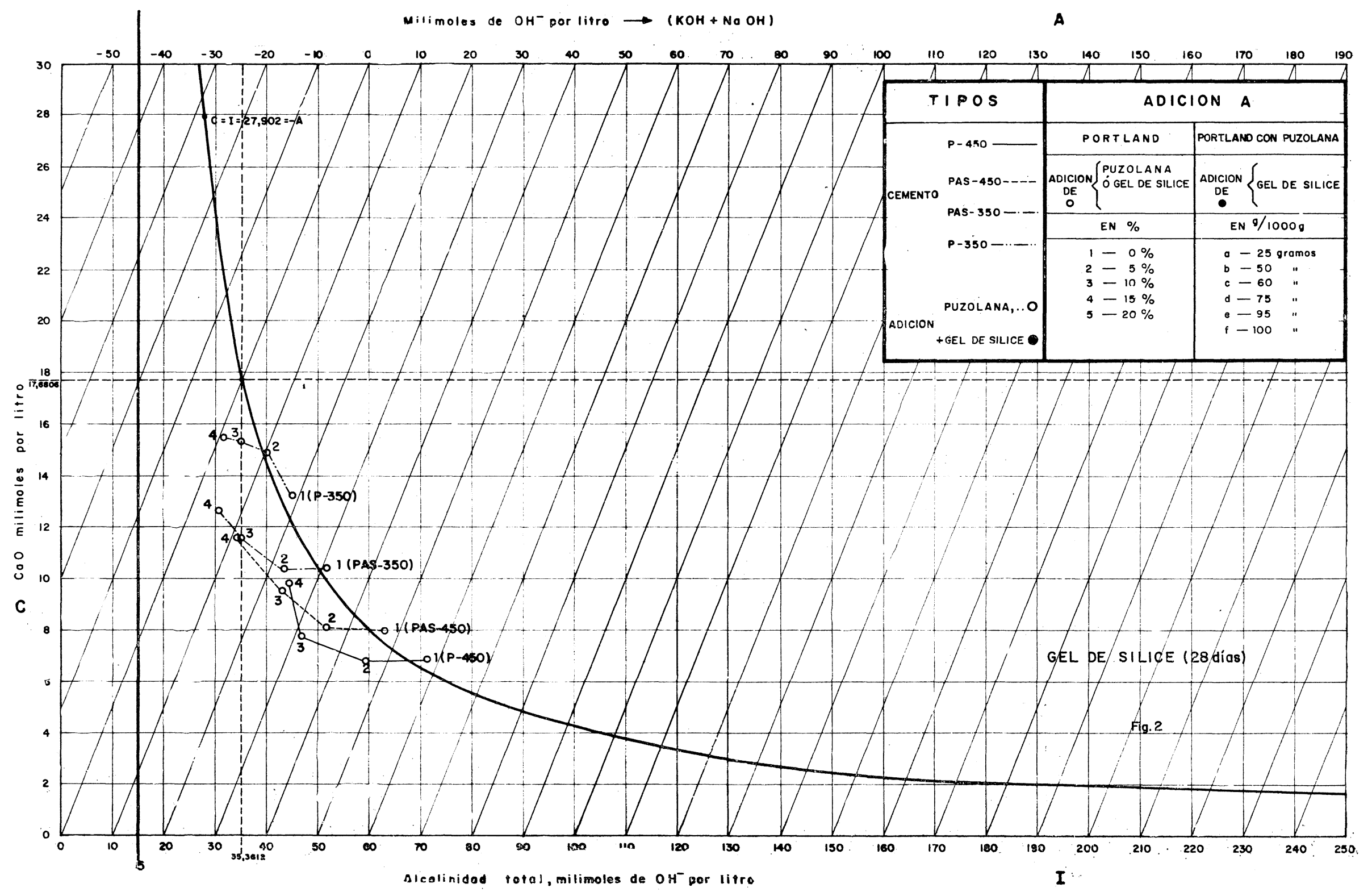


CURVA ISOTERMA DE SOlUBILIDAD A $40^{\circ} \mathrm{C}$ DE $\mathrm{Ca}(\mathrm{OH})_{2}$, EN PRESENCIA DE ALCALIS, DE NICOLA fRATINI, TOMADA PARA EL ENSAYO DE PUZOLANICIDAD

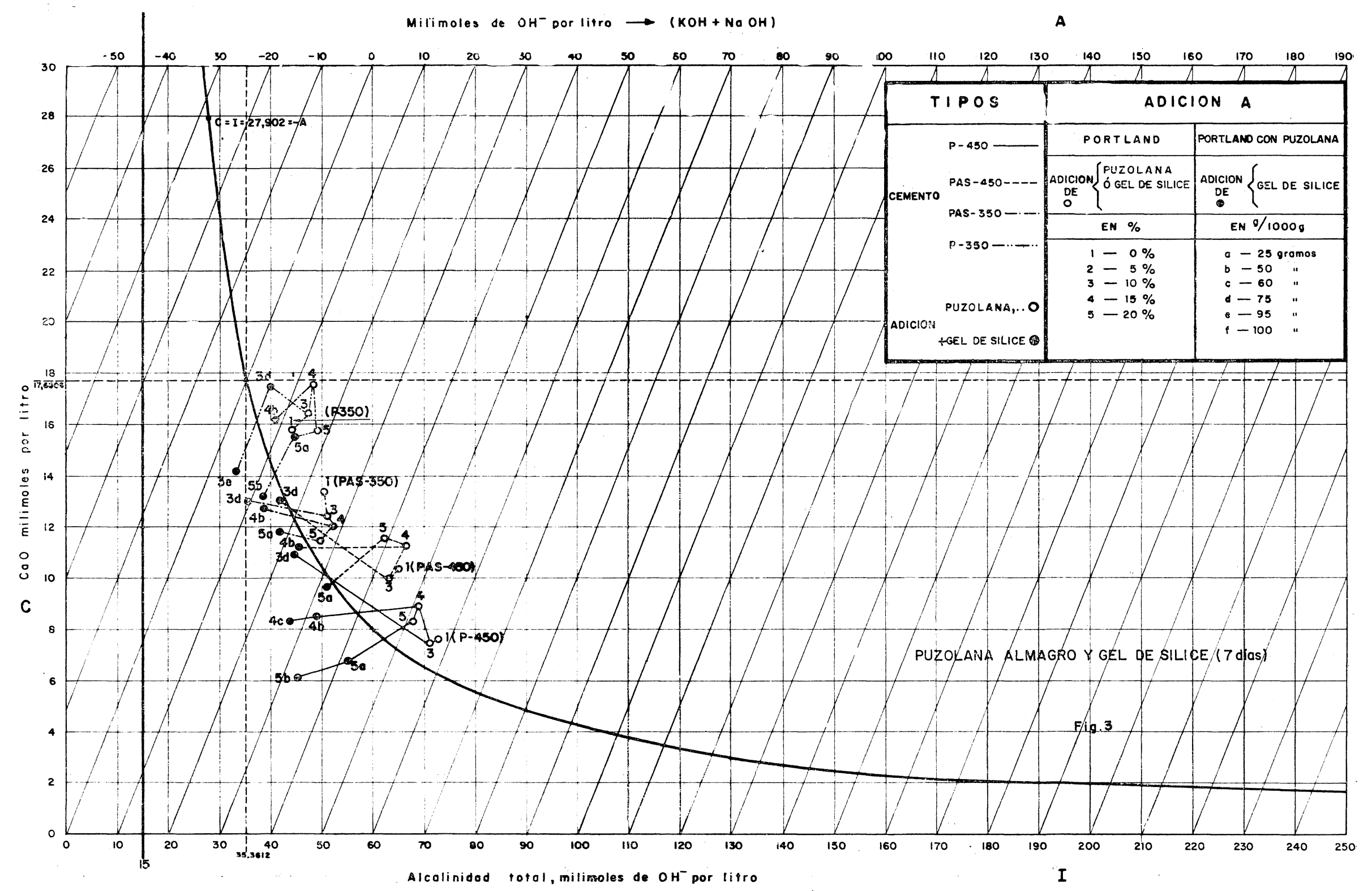


CURVA ISOTERMA DE SOLUBILIDAd A $40^{\circ} \mathrm{C}$ DE $\mathrm{Ca}(\mathrm{OH})_{2}$, EN PRESENCIA DE ALCALIS, DE NICOLA FRATINI, TOMADA PARA EL ENSAYO DE PUZOLANICIDAD

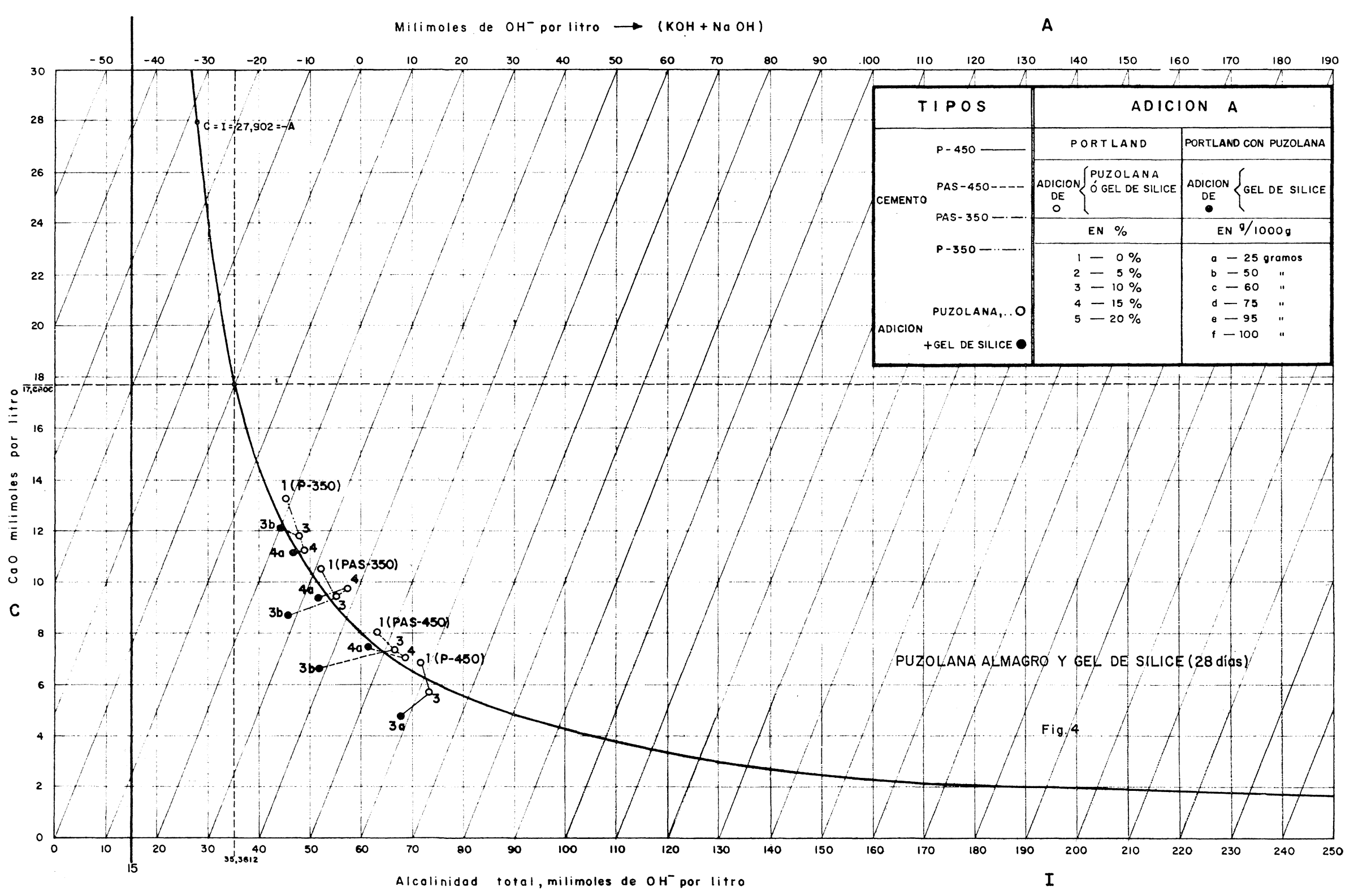


CURVA ISOTERMA DE SOLUBILIDAd A $40^{\circ} \mathrm{C}$ DE $\mathrm{Ca}(\mathrm{OH})_{2}$, EN PRESENCIA DE ALCALIS, DE NICOLA FRATINI, TOMADA PARA EL ENSAYO DE PUZOLANICIDAD

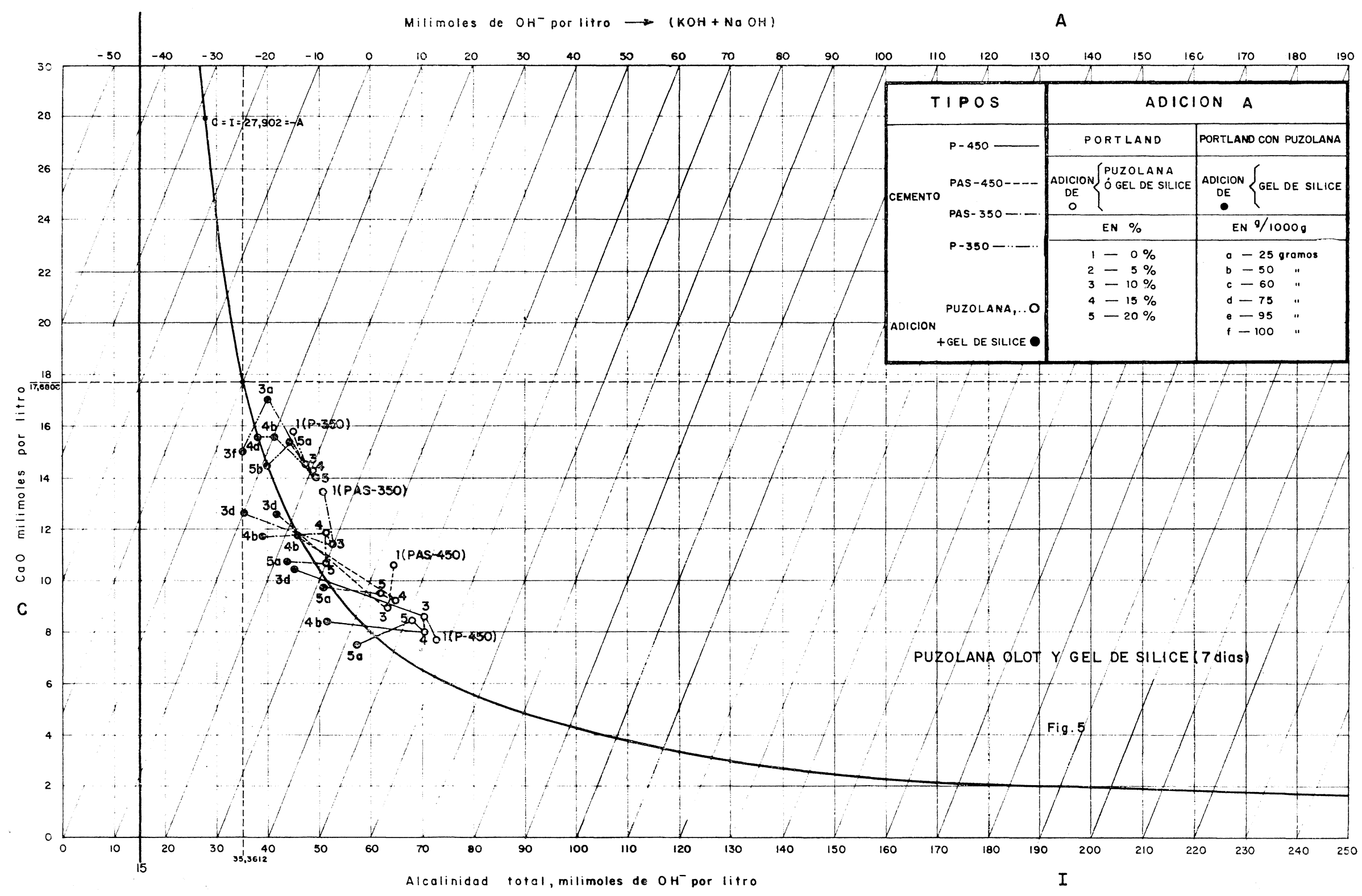


CURVA ISOTERMA DE SOlUbILIDAD A $40^{\circ} \mathrm{C}$ DE $\mathrm{Ca}(\mathrm{OH})_{2}$, EN PRESENCIA DE ALCALIS, DE NICOLA FRATINI, TOMADA PARA EL ENSAYO DE PUZOLANICIDAD

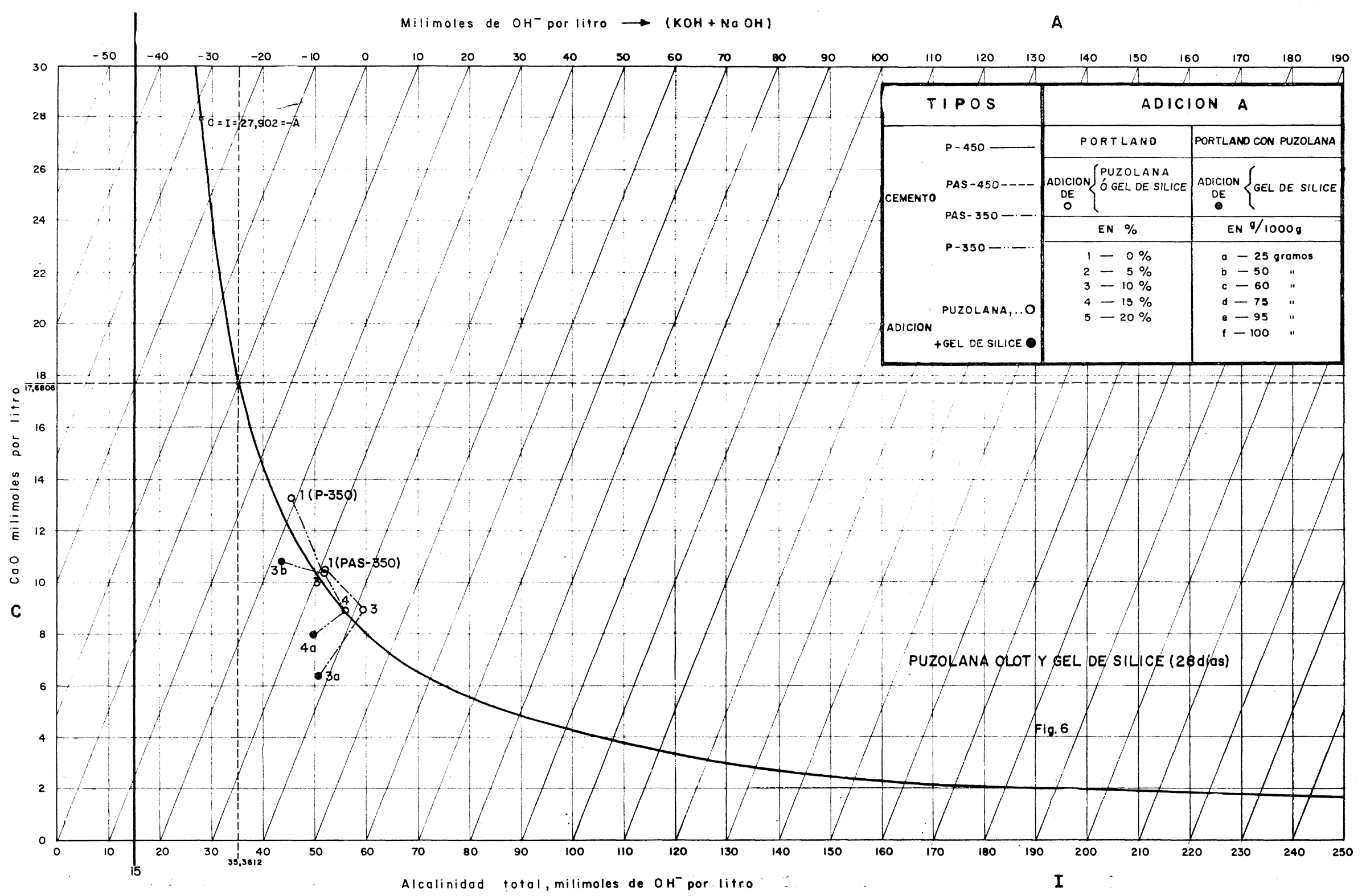




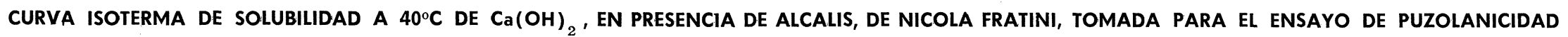

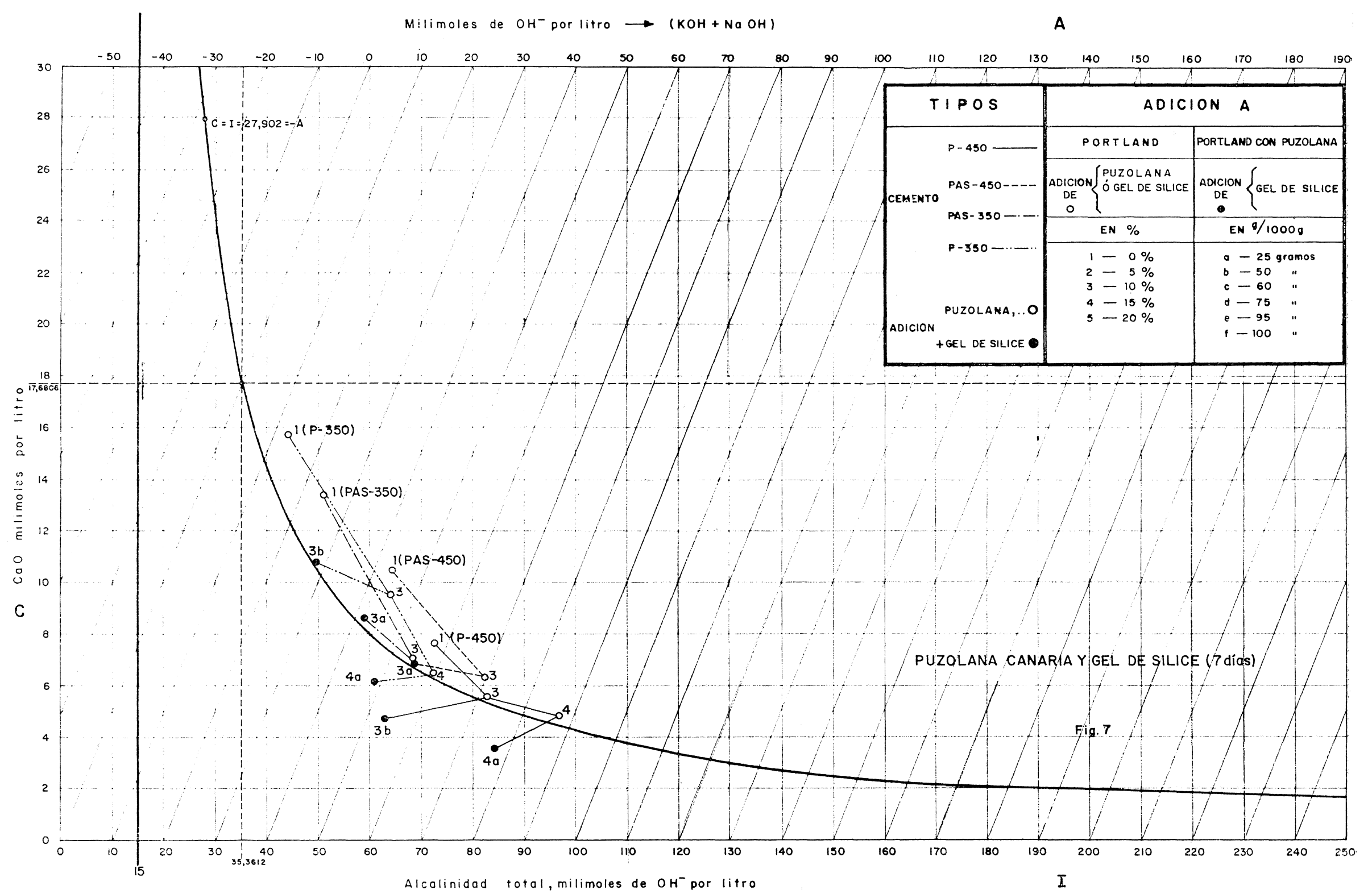


CURVA ISOTERMA dE SOlUbILIDAD A $40^{\circ} \mathrm{C}$ DE $\mathrm{Ca}(\mathrm{OH})_{2}$, EN PRESENCIA DE ALCALIS, DE NICOLA FRATINI, TOMADA PARA EL ENSAYO DE PUZOLANICIDAD

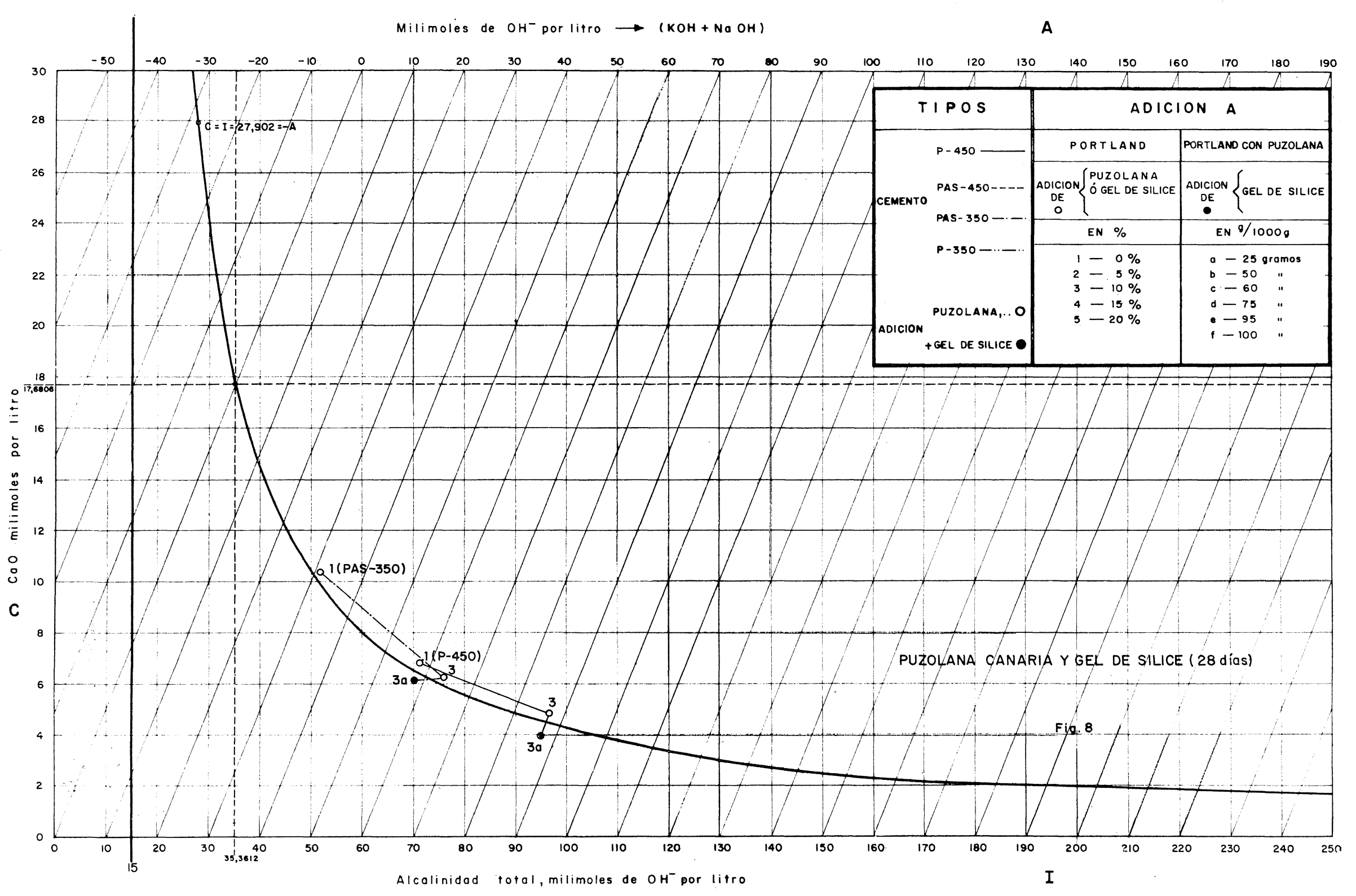




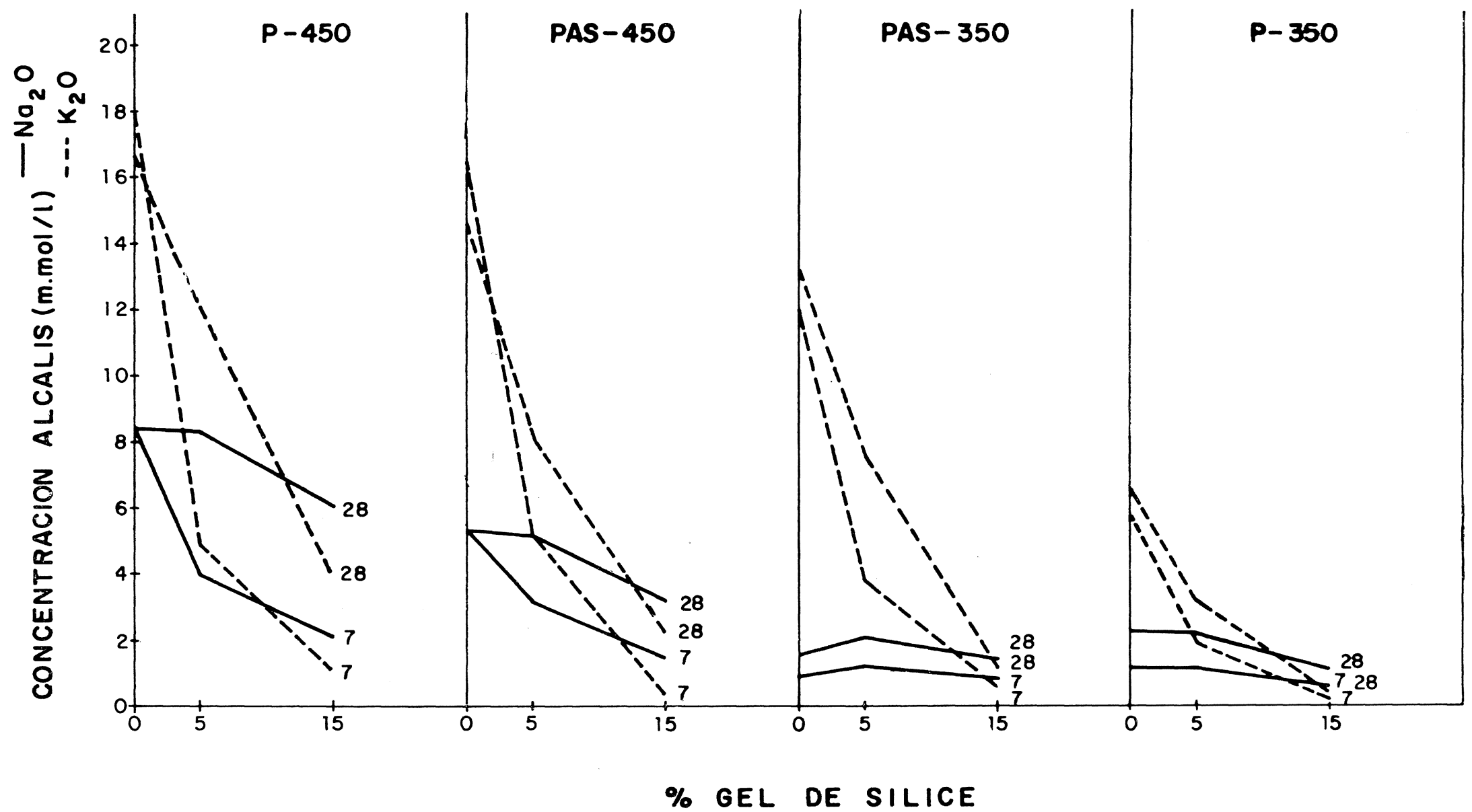

Fig. 9. Concentración en álcalis de las disoluciones en contacto con las pastas de cemento portland que contienen gel de sílice a las edades de 7 y 28 días. 